Open Access to Pharmaceutical and Medical Research
uDDT* so

Open $\odot$ Access

Review Article

\title{
A Review on Comparison of Effectiveness and Safety of Disease Modifying Anti-Rheumatoid Drugs Used in Patients with Rheumatoid Arthritis
}

\author{
P.P Muhamed Faris, K. Sreejith*, B. Athulnadh, K.V. Musaina Thasneem, Cherakkulath C. Neena, Namitha \\ Maniyan
}

Department of Pharmacy Practice, College of Pharmaceutical Sciences, Govt. Medical College, Kozhikode, Kerala, 673008, India

\begin{abstract}
Objective: To compare the safety and effectiveness of monotherapy as well as combination therapy with disease modifying anti rheumatoid drugs (DMARDs) in rheumatoid arthritis patients.

Data sources: Study works limited to the English language and more concentrated to adults by using Google Scholar, PubMed and The Cochrane library.

Summary: Some head to head trial works, retrospective studies and prospective cohort studies were used to compare the safety and effectiveness of the therapy. Here we go through the comparison in between each disease modifying anti rheumatoid drug (DMARD) monotherapy, combination with monotherapy and also combination with combination therapy.

Conclusion: Among the synthetic DMARDs monotherapy, methotrexate would be the preferred DMARD. Biological DMARDs have more efficacy than synthetic agents and have comparable safety profile. Rituximab would be the preferred agent among the bDMARDs. Since synthetic agents are more economical as compared to biologicals, hence these are preferred over biological agents. Combinations of biological DMARDs with methotrexate have improved efficacy and safety than methotrexate monotherapy. Combination of biological DMARDs have no advantage over biological monotherapy, there was an increased safety risk and no therapeutic benefit. Combination of biological DMARDs with methotrexate have better efficacy than monotherapy with either bDMARDs or methotrexate alone. A triple combination therapy of synthetic DMARDs (methotrexate, sulfasalazine and hydroxychloroquine) had better safety, effectiveness and high tolerability than double combination therapy or monotherapy.
\end{abstract}

Keywords: Rheumatoid arthritis, disease modifying antirheumatoid drugs

Article Info: Received 02 Sep 2020; $\quad$ Review Completed 13 Oct 2020; $\quad$ Accepted 23 Oct 2020; Available online 15 Nov 2020

Cite this article as:

Faris PPM, Sreejith K, Athulnadh B, Thasneem KVM, Neena CC, Maniyan N, A Review on Comparison of Effectiveness and Safety of Disease Modifying Anti-Rheumatoid Drugs Used in Patients with Rheumatoid Arthritis, Journal of Drug Delivery and Therapeutics. 2020; 10(6):207-212 http://dx.doi.org/10.22270/jddt.v10i6.4535

*Address for Correspondence:

K. Sreejith, Department of Pharmacy Practice, College of Pharmaceutical Sciences, Govt. Medical College, Kozhikode, Kerala, 673008, India

\section{Introduction}

Rheumatoid arthritis is an autoimmune disease that characterized by the symmetrical inflammation of the peripheral joints and other extra articular regions. Actual cause of rheumatoid arthritis is unknown. it is facilitated by some factors like genetic factors, environmental factors and immunological factors. ${ }^{1}$ RA is a progressive inflammatory joint disorder, in which patients may experience alternating episodes of joint stiffness, levels of pain and swelling. A better treatment option will facilitates the improvements in the quality of life and to prevent the progression of the disease. Treatment should be started as earlier as possible which helps to improve the quality of life mainly by control of structural damage, reducing the symptoms, improvements in the functional status, and social participation. ${ }^{2}$

Disease modifying anti rheumatoid drugs (DMARDs), Nonsteroidal anti-inflammatory drugs (NSAIDs) and corticosteroids are the class of drugs used in rheumatoid arthritis. Since DMARDs are not able to give complete remission if the disease was too old, hence they are used to control the disease progression. It is better to start the DMARD therapy as earlier as possible after the diagnosis. Treatment outcomes will be better when the DMARDs are started within three months of diagnosis. Cumulative toxicity and frequent adverse events are the important problems of the drug treatment. ${ }^{3}$ 
A better therapeutic strategy have better outcome that can be observed by the absence of, the symptoms of active inflammatory joint pain, fatigue, morning stiffness, synovitis and erythrocyte sedimentation rate or C-reactive protein (CRP) level etc. ${ }^{4}$ continuous use of DMARDs are meant for the treatment of RA to control the disease progression. Most of the DMARDs are having delayed action. The sudden onset of pain or severe pain and joint discomfort etc are managed by the help of NSAIDs, but which was not preferred due to the serious side effects like gastro intestinal complications or other intolerance. ${ }^{5}$ In such cases low dose corticosteroids are preferred. ${ }^{6}$

The safety can be measured through the patient reported outcomes. The functional status is determined by questionnaires such as health assessment questionnaire (HAQ), health assessment questionnaire disability index (HAQ-DI), multi-dimensional health assessment questionnaire (MDHAQ) and shortform 36 (SF36). The pain severity can be measured by the use of rheumatoid arthritis pain scale (RAPS) questionnaire. ${ }^{7}$

\section{Comparative effectiveness and adverse events}

We found some data from the literatures to compare the safety and effectiveness of discrete drugs and also from the combinations. Disease activity score (DAS), physician global assessment, patient global assessment, number of swollen joints and number of tender joints, erythrocyte sedimentation rate (ESR), C-reactive protein (CRP), rheumatoid factor (RF) etc are used to measure clinical improvements. Also measures the radiographic progression of the disease. The Quality of life is measured by the use of HAQ, SF-36 or RAPS etc.

\section{Comparison of Monotherapy}

\section{(a) Synthetic/nonbiological DMARDs}

\section{Methotrexate vs Leflunomide:}

Methotrexate showed better improvements in patient global assessment, physician global assessment number of swollen joints, number of tender joints, erythrocyte sedimentation rate and C-reactive protein level than patients who treated with leflunomide. Patients receiving MTX showed less improvement in HRQOL as compared to leflunomide. Radiographic outcome of the disease by both these agents were similar upto two years. After two years, progression of the disease was well controlled in patients under methotrexate therapy. Alopecia, skin rash, tendency to vomiting, diarrhoea and increased level liver enzymes etc were more commonly reported adverse events on both methotrexate and leflunomide monotherapy. A two years study showed that 21 patients withdrawn methotrexate and 8 patients withdrawn leflunomide due to elevated plasma liver enzyme. ${ }^{8}$ Diarrhea, allergic or sensitive reactions mostly like pruritus and skin rash were more commonly reported with leflunomide monotherapy, whereas pneumonia and bronchitis were more commonly reported with methotrexate monotherapy. ${ }^{9}$

\section{Leflunomide vs sulfasalazine:}

Leflunomide showed better results in functional status in ACR 20, ACR 50 and HRQOL than sulfasalazine, but the radiographic outcomes were similar. Leflunomide was well tolerated than sulfasalazine. There was no longterm safety issues in the treatment of rheumatoid arthritis who on continuous treatment with leflunomide over two years. ${ }^{10}$ The beneficial effects of sulfasalzine was only to a shorter period, gastro-intenstinal adverse effects are the main reason for the treatment withdrawal.11

\section{Methotrexate vs sulfasalazine:}

Patients treated with sulfasalazine were periodically become RF negative. They have faster in their action, but the beneficial effect was only extended to a shorter period of time during the entire treatment, later the effectiveness was reduced. Adherence rate was better in case of MTX rather than sulfasalazine. SSZ was less effective when compared with methotrexate. 12 Stomach upset, loss of appetite, headache, tiredness etc are the commonly reported adverse effects of sulfasalazine therapy.11

Methotrexate was well tolerated. Studies showed that it has better safety and efficacy in rheumatoid arthritis patients. Especially, it reduces symptoms of the disease, patient disability and shows improvements in the structural damages and physical functioning of the patients than other synthetic DMARDs. Leflunomide and methotrexate shows similar effectiveness. Sulfasalazine and injectable gold monotherapy also reduces symptoms of the disease and shows improvements in structural as well as functional activity. Tacrolimus, ciclosporin, hydroxy-chloroquine and minocyclin monotherapy have activity to reduce swollen joint count. Auranofin and D-Penicillamine does not shows significant changes in the disease progression. The use of azathioprine and cyclophosphamide was less effective, although there is an increased risk of serious infections and cancer. ${ }^{13}$

\section{(b) Biological DMARDs}

\section{Etanercept vs infliximab:}

After the diagnosis, during the first few months of etanercept therapy have better response but on the continuous therapy the beneficial effect was reduces gradually. Patients were more adhered towards etanercept therapy. The rate of serious infections were comparable in both etanercept and infliximab monotherapy. According to United States FDA reports infliximab showed increased risk of granulomatous infection as compared to etanercept. ${ }^{14}$ In another study the patient noncompliance or withdrawal rates were higher for infliximab compared with etanercept, the noncompliance was arised due to some safety related issues of the drugs. 15

Studies showed that there were no significant differences within the class of anti-TNF agents that includes etanercept, adalimumab, golimumab and infliximab etc in their efficacy by comparing the ACR 20 and ACR 50 response etc. ${ }^{16}$ In a meta-analysis by considering the ACR50 response there was no significant difference in between rituximab, tocilizumab, golimumab and abatacept. ${ }^{17}$

Injection site reactions were mostly reported in patients who under continuous treatment with anakinra. The risk was lesser in case of adalimumab. Anakinra has lesser efficacy among the anti-TNF drugs. Anakinra showed lesser response towards ACR 20 and ACR 50 etc. Etanercept was safer than adalimumab, anakinra and infliximab. The adherence rate towards anakinra treatment was less as compared to etanercept or infliximab due to the safety issues. ${ }^{18}$

Randomized clinical studies showed that rituximab and abatacept are more effective thanother DMARDs which are inadequate to control the disease. Abatacept and rituximab shows similarity in their effectiveness. The studies suggested that rituximab have better efficacy and safety over adalimumab, etanercept and infliximab. A prospective observational study supported that, a beneficial effect will be obtained by the addition of an anti-tumor necrotic factor agent to the RA patients in which they had experienced an adequate action with a prior anti-tumor necrotic factor agent. 19 


\section{New biological agents:}

\section{Rituximab}

It is amonoclonal antibody having action on B cells. It has specific action towards B cell CD20 antigen by variety of mechanisms. It was previously used in the treatment of hodgkins lymphoma, now a day it is used in the case of RA patients, those which Anti-TNf agents are totally failed. Rituximab reduce the level of rheumatoid factor but the mechanism was still unknown. In a six months phase II trial, use of rituximab along with methotrexate therapy in RA patients with positive rheumatoid factor having better efficacy than methotrexate monotherapy. Infusion reactions are the most commonly reported adverse effect with rituximab. Symptoms include chills, fever, angioedema, throat irritation, cough, bronchospasm, hypo/ hypertension and skin rashes etc. Multifocal leuco-encephalopathy in association with systemic lupus erythomatosus was reported by USFDA in rheumatoid arthritis patients who are under the rituximab therapy. Chronic use of rituximab results sustained IgM deficiency. ${ }^{20,22}$

\section{Abatacept}

It is a modified antibody composed of FC region of IgG1 immunoglobulin fused with extracellular domain of CTLA4. The resultant molecule has better affinity towards CD28. It is used to treat rheumatoid arthritis as a secondline agent and the likelihood autoimmune diseases. Abatacept interfere with $\mathrm{T}$ cell activation by competes with CD28 for binding of CD80 and CD86. Abatacept and infliximab having similar in efficacy while abatacept has lower side effects as compared to infliximab. Increased frequency of infections, include serious infections. Serious infections were mostly reported in combination with etanercept even the efficacy was same. Addition of Abatacept to anti TNF agents like adalimumab, infliximab, etanercept and anakinra (IL-1 antagonist) doesnot have additional efficacy, however a four times enhanced infection rate was reported. 21,22

\section{Tocilizumab}

Monotherapy with $2 \mathrm{mg} / \mathrm{kg}$ (low dose) Tocilizumab is useless, better result was obtained by the use of $8 \mathrm{mg} / \mathrm{kg}$ dose. Enhanced efficacy was reported when tocilizumab combined with methotrexate. DAS28 response rate was improved with respect to dose. Tender joint counts, number of swollen joints, health assessment questionnaire, health assessment questionnaire with disability index etc are improved. Clinical adverse events include headache, skin eruptions, stomatitits, and fever. Serious anaphylactic reactions or hypersensitivity reactions are more common in patients receiving low dose of tocilizumab monotherapy $(2 \mathrm{mg} / \mathrm{kg})$. Mild anaphylactic reactions were reported in $4 \mathrm{mg} / \mathrm{kg}$ tocilizumab monotherapy and $2 \mathrm{mg} / \mathrm{kg}$ tocilizumab with MTX combination therapy. Less than $8 \%$ of patients in which serious infections were reported whom under the tocilizumab monotherapy. It also alters some laboratory values like neutropenia. It affects the liver function by elevated enzymes and also alters the lipid profile. Tocilizumab therapy increased cholesterol and triglyceride level.22

\section{(c) Synthetic agent vs biological agent:}

Patients on biological DMARDs having increased risk towards serious infections like tuberculosis and may have increased risk of melanoma than the patients with synthetic DMARDs. ${ }^{23}$ Anti tumor necrotic factor agents having better safety and efficacy especially in long established cases of active rheumatoid arthritis. Anti TNF agents are well tolerated over methotrexate. When compared with methotrexate, the therapeutic response by anti tumor necrotic factor agent is unaffected by the preceeding DMARD history. ${ }^{24}$

\section{Methotrexate vs adalimumab or etanercept}

Head to head comparison studies showed that when comparing with methotrexate, etanercept have better efficacy and it shows better improvements in the symptoms of rheumatoid arthritis except in radiographic progression. Etanercept have good tolerability and with an enhanced adherence rate over methotrexate. When compared with methotrexate, both these agents (etanercept and adalimumab) have better control for the prevention of structural damage, it reduces the chances of bony erosions and offer better quality of life. ${ }^{25}$

\section{Methotrexate vs tocilizumab}

Tocilizumab shows statistically superior clinical efficacy over methotrexate in early rheumatoid arthritis. Tocilizumab has an effect to anemia correction, commonly linked with rheumatoid arthritis which effect was not seen with methotrexate. Tocilizumab shows rapid improvements in CRP, ESRand inhibit the progression of joint damage. Incidence of adverse events are comparable in both, increased total cholesterol, LDL and HDL level were seen in patients under tocilizumab therapy. ${ }^{26}$

\section{Combination therapy vs monotherapy}

(a) Combination of synthetic DMARDs vs methotrexate:

Combination of synthetic DMARD with methotrexate shows clinically better advantage over monotherapy with methotrexate. Studies showed a better efficacy by the reduction of joint stiffness, pain, swollen joints and improvement in cognitive functions.

\section{Leflunomide with methotrexate vs methotrexate}

Here the combination therapy is a cost effective method. This combination had better therapeutic potential and it was well tolerated, but there was an increased opportunity to intolerable gastro-intestinal side effects, hypertension, pancytopenia, infections and hepatotoxicity. 27 The only serious adverse event reported was asymptomatic elevation of the plasma liver transaminase enzyme. ${ }^{28}$

\section{Cyclosporine with methotrexate vs methotrexate}

Combination therapy is better to MTX monotherapy to improve clinical disease activity and slowing radiographic progression of the disease, without any serious adverse effects. ${ }^{29}$

\section{Sulfasalazine with methotrexate vs methotrexate}

Sulfasalazine with methotrexate combination was proved effective over methotrexate monotherapy. It was also better than the sulfasalazine monotherapy too. There was an increase in toxicity profile especially in the antifolate activity. ${ }^{30}$

\section{Gold compound with methotrexate vs methotrexate}

The addition of parentral gold preparation to methotrexate had significant advantage in reducing disease activity in patients with long established cases of rheumatoid arthritis. There was no additional risk of toxicity. ${ }^{31}$

\section{Hydroxychloroquine with methotrexate vs methotrexate}

The hepatotoxicity of methotrexate decreasing with the help of HCQ by enhancing the size as well as increasing the number of lysosomes within the lysosomal membrane. ${ }^{32}$ 


\section{(b) Combination of bDMARDs with methotrexate vs methotrexate:}

Etanercept with methotrexate vs methotrexate

Combination of etanercept with MTX have better safety and efficacy than monotherapy with methotrexate significantly in patients having adult onset RA. ${ }^{33}$ The combination was safe and well tolerated. ${ }^{34}$

\section{Adalimumab with methotrexate vs methotrexate}

Adalimumab and the methotrexate combination showed improvements with longstanding RA, there are no safety issues. Adalimumab with leflunomide combination was less effective as compared with MTX combination. ${ }^{35}$

Infliximab with methotrexate vs methotrexate

Addition of infliximab to methotrexate therapy showed better activity. It reduces the joint stiffness, pain and other functional difficulties. It was well tolerated. Quality of life was better with the combination. 36

\section{Anakinra with methotrexate vs Methotrexate}

The addition of anakinra to methotrexate therapy was safer. It has significantly better tolerance. Studies showed that the combination have better therapeutic benefit over monotherapy with methotrexate. 37

\section{(c) Combination of biological DMARDs vs monotherapy:}

\section{Etanercept with Anakinra vs etanercept}

Combined use of etanercept with anakinra had no significant therapeutic benefit. Thus it is not recommended as combination for the treatment of rheumatoid arthritis due to its extensive risk over benefits. ${ }^{38}$

\section{(d) Combination of biological DMARD with MTX vs biological DMARD:}

Etanercept with methotrexate vs etanercept

Combined use of MTX with etanercept in RF positive rheumatoid arthritis patients had shown better efficacy and safety than etanercept alone. ${ }^{39}$ etanercept monotherapy have adequate safety and efficacy even though the combination have improved activity especially in the case of juvenile idiopathic arthritis. Patient satisfaction and adherence rate was comparable in both these groups. ${ }^{40}$

\section{Adalimumab with methotrexate vs adalimumab}

Patients with early, aggressive RA, combination of adalimumab with methotrexate had superior efficacy than adalimumab alone in controlling of the disease. Combined therapy have better efficacy to inhibit the progression of radiographic changes or structural damage and also have better improvements in physical or cognitive functions as compared to monotherapy with either adalimumab alone or methotrexate alone. ${ }^{41}$

\section{(e) Combination of biological DMARD with DMARD other than MTX vs biological DMARD:}

\section{Etanercept with sulfasalazine vs etanercept}

Studies showed that, there was a rapid response is given by the combined use of etanercept with sulfasalazine therapy, The treatment outcome was better in the case of combination therapy when compared with monotherapy of both. ${ }^{41}$ Headache, nausea and asthenia were more commonly reported in the case of combination rather than etanercept alone. Infection rate and injection site reactions are more common with etanercept monotherapy. ${ }^{42}$

\section{Combination therapy vs combination therapy}

Combination therapy with methotrexate, sulfasalazine and hydroxychloroquine showed better effectiveness than the combination of sulfasalazine with hydroxychloroquine, there was no increase in toxicity profile. ${ }^{43}$ These three item combined therapy (methotrexate, hydroxyl chloroquine and sulfasalazine) also showed superior efficacy and comparatively well tolerability than the combination of methotrexate and sulfasalzine and also to methotrexate with hydroxychloroquine combination. ${ }^{44}$

\section{Conclusion}

Among the synthetic disease modifying antirheumatoid drugs monotherapy, methotrexate has a much stronger potential for suppressing the development of erosions which would support that, it is being the preferred DMARD. Biological DMARDs have more efficacy than synthetic agents and have comparable safety profile. Rituximab would be a better agent among the biologicals which have better safety and well efficacy. Since synthetic agents are more economical as compared to biologicals, hence these are preferred over biological agents. Combinations of biological DMARDs with methotrexate have improved efficacy and safety than methotrexate monotherapy. Combination of biological DMARDs have no advantage over biological monotherapy, there was an increased safety risk and no therapeutic benefit. Combination of biological DMARDs with methotrexate have better efficacy than monotherapy with either bDMARDs or methotrexate alone. A triple combination therapy of synthetic DMARDs (methotrexate, sulfasalazine and hydroxychloroquine) had better safety, effectiveness and high tolerability than double combination therapy or monotherapy.

\section{References}

1. Huber LC, Distler O, Tarner I, Gay RE, Gay S, Pap T. Synovial fibroblasts: key players in rheumatoid arthritis. Rheumatology. 2006 Jun 1; 45(6):669-75.

2. Buckley F, Finckh A, Huizinga TW, Dejonckheere F, Jansen JP. Comparative efficacy of novel DMARDs as monotherapy and in combination with methotrexate in rheumatoid arthritis patients with inadequate response to conventional DMARDs: a network meta-analysis. Journal of managed care \& specialty pharmacy. 2015 May; 21(5):409-23.

3. Malysheva OA, Wahle M, Wagner U, Pierer M, Arnold S, Haentzschel H, Baerwald CG. Low-dose prednisolone in rheumatoid arthritis: adverse effects of various disease modifying antirheumatic drugs. The Journal of rheumatology. 2008 Jun 1; 35(6):979-85.

4. Farheen K, Agarwal SK. Assessment of disease activity and treatment outcomes in rheumatoid arthritis. Journal of Managed Care Pharmacy. 2011 Nov; 17(9 Supp B):S09-13.

5. Singh G, Ramey DR, Morfeld D, Shi H, Hatoum HT, Fries JF. Gastrointenstinal tract complications of nonsteroidal anti inflammatory drug treatment in rheumatoid arthritis: a prospective observational cohort study. Archives of internal medicine. 1996 Jul 22; 156(14)1530-6.

6. Caldwell JR, Furst DE. The efficacy and safety of low dose corticosteroids for rheumatoid arthritis. Inseminars in arthritis and rheumatism 1991 Aug 1; (21):1-11

7. Strand V, Tugwell P, Bombardier C, Maetzel A, Crawford B Dorrier C, Thompson A, Wells G. Function and health-related quality of life: results from a randomized controlled trial of leflunomide versus methotrexate or placebo in patients with active rheumatoid arthritis. Arthritis \& Rheumatism: Official Journal of the American College of Rheumatology. 1999 Sep; 42(9):1870-8.

8. Emery P, Breedveld FC, Lemmel EM, Kaltwasser JP, Dawes PT, Gömör B, Van den Bosch F, Nordström D, Bjørneboe O, Dahl R, Hørslev-Petersen K. A comparison of the efficacy and safety of leflunomide and methotrexate for the treatment of rheumatoid arthritis. Rheumatology. 2000 Jun 1; 39(6):65565. 
9. Strand V, Cohen S, Schiff M, Weaver A, Fleischmann R, Cannon G, Fox R, Morland L, Olsen N, Furst D, Caldwell J. treatment of active rheumatoid arthritis with leflunomide compared with placebo and methotrexate. Archives of internal medicine. 1999 nov 22; 159(21):2542-50.

10. Cohen S, Cannon GW, Schiff M, Weaver A, Fox R, Olsen N, Furs D, Sharp J, Moreland L, Caldwell J, Kaine J. Two-year, blinded, randomized, controlled trial of treatment of active rheumatoid arthritis with leflunomide compared with methotrexate. Arthritis \& Rheumatism: Official Journal of the American College of Rheumatology. 2001 Sep; 44(9):1984-92.

11. Egsmose C, Hansen TM, Andersen LS, Beier JM, Christensen L, Peters ND, Van der Heijde DM. Limited effect of sulfasalazine treatment in reactive arthritis. A randomized double blind placebo controlled trial. Annals of the rheumatic diseases. 1997 Jan 1; 56(1):32-6

12. Haagsma CJ, Van Riel, De Jong AJ, Van De Putte LB. Combination of sulfasalazine and methotrexate versus the single components in early rheumatoid arthritis: a randomized controlled, double blind, 52 week clinical trial. British journal of rheumatology. 1997 Oct 1; 36(10):1082-8

13. Gaujoux-Viala C, Smolen JS, Landewé R, Dougados M, Kvien TK, Mola EM, Scholte-Voshaar M, van Riel P, Gossec L. Current evidence for the management of rheumatoid arthritis with synthetic disease-modifying antirheumatic drugs: a systematic literature review informing the EULAR recommendations for the management of rheumatoid arthritis. Annals of the rheumatic diseases. 2010 Jun 1; 69(6):1004-9.

14. Haraoui B, Keystone EC, Thorne JC, Pope JE, Chen I, Asare CG, Leff JA. Clinical outcomes of patients with rheumatoid arthritis after switching from infliximab to etanercept. The journal of rheumatology. 2004 Dec 1; 31(12):2356-9

15. Flouri I, Markatseli TE, Voulgari PV, Boki KA, Papadopoulos I, Settas L, Zisopoulos D, Skopouli FN, Iliopoulos A, Bertsias GK, Geborek P. Comparative effectiveness and survival of infliximab, adalimumab, and etanercept for rheumatoid arthritis patients in the Hellenic Registry of Biologics: Low rates of remission and 5-year drug survival. InSeminars in arthritis and rheumatism 2014 Feb 1; 43(4):447-457). WB Saunders.

16. Greenberg JD, Reed G, Decktor D, Harrold L, Furst D, Gibofsky A, DeHoratius R, Kishimoto M, Kremer JM. A comparative effectiveness study of adalimumab, etanercept and infliximab in biologically naive and switched rheumatoid arthritis patients: results from the US CORRONA registry. Annals of the rheumatic diseases. 2012 Jul 1; 71(7):1134-42.

17. Salliot C, Finckh A, Katchamart W, Lu Y, Sun Y, Bombardier C, Keystone E. Indirect comparisons of the efficacy of biological antirheumatic agents in rheumatoid arthritis in patients with an inadequate response to conventional disease-modifying antirheumatic drugs or to an anti-tumour necrosis factor agent: a meta-analysis. Annals of the rheumatic diseases. 2011 Feb 1; 70(2):266-71.

18. Singh JA, Christensen R, Wells GA, Suarez-Almazor ME, Buchbinder R, Lopez-Olivo MA, Ghogomu ET, Tugwell P. A network meta-analysis of randomized controlled trials of biologics for rheumatoid arthritis: a Cochrane overview. Cmaj. 2009 Nov 24; 181(11):787-96.

19. Malottki K, Barton P, Tsourapas A, Uthman AO, Liu Z, Routh K, Connock M, Jobanputra P, Moore D, Fry-Smith A, Chen YF. Adalimumab, etanercept, infliximab, rituximab and abatacept for the treatment of rheumatoid arthritis after the failure of a tumour necrosis factor inhibitor: a systematic review and economic evaluation. InNIHR Health Technology Assessment programme: Executive Summaries 2011. NIHR Journals Library.

20. Brownish JL. B cells move to centre stage: novel opportunities for auto immune disease treatment. Nature reviews drug discovery. 2006 Jul; 5(7):564.

21. Linsley PS, Brady W, Urnes M, Grosmaire LS, Damle NK, Ledbetter JA. CTLA4 is a second receptor for the B cell activation antigen B7. Journal of experimental medicine. 1991 Sep 1; 174(3):561-9

22. Smolen JS, Aletaha D, Koelller M, Weisman H, Emery P. New therapies for treatment of rheumatoid arthritis. The lancet. 2007 Dec 1; 370(9602):1861-74

23. Ramiro S, Sepriano A, Chatzidionysiou K, Nam JL, Smolen JS, Van Der Heijde D, Dougados M, Van Vollenhoven R, Bijlsma JW
Burmester GR, Scholte-Voshaar M. Safety of synthetic and biological DMARDs: a systematic literature review informing the 2016 update of the EULAR recommendations for management of rheumatoid arthritis. Annals of the rheumatic diseases. 2017 Jun 1; 76(6):1101-36.

24. Barrera P, van Der Maas A, Van Ede AE, Kiemeney BA, Laan RF, Van de Putte LB, van Riel PL. Drug survival, efficacy and toxicity of monotherapy with a fully human anti-tumour necrosis factor- $\alpha$ antibody compared with methotrexate in long-standing rheumatoid arthritis. Rheumatology. $2002 \mathrm{Apr}$ $1 ; 41(4): 430-9$.

25. Chen YF, Jobanputra P, Barton P, Jowett S, Bryan S, Clark W, Fry-Smith A, Burls A. A systematic review of the effectiveness of adalimumab, etanercept and infliximab for the treatment of rheumatoid arthritis in adults and an economic evaluation of their cost-effectiveness. InNIHR Health Technology Assessment programme: Executive Summaries 2006. NIHR Journals Library.

26. Jones G, Sebba A, Gu J, Lowenstein MB, Calvo A, Gomez-Reino JJ, Siri DA, Tomšič M, Alecock E, Woodworth T, Genovese MC. Comparison of tocilizumab monotherapy versus methotrexate monotherapy in patients with moderate to severe rheumatoid arthritis: the AMBITION study. Annals of the rheumatic diseases. 2010 Jan 1; 69(01):88-96.

27. Katchamart W, Trudeau J, Phumethum V, Bombardier C. Methotrexate monotherapy versus methotrexate combination therapy with non-biologic disease modifying anti-rheumatic drugs for rheumatoid arthritis. Cochrane database of systematic reviews. 2010(4).

28. Weinblatt ME, Kremer JM, Coblyn JS, Maier AL, Helfgott SM, Morrel M, Byrne VM, Kaymakcian MV, Strand V. Pharmacokinetics, safety, and efficacy of combination treatment with methotrexate and leflunomide in patients with active rheumatoid arthritis. Arthritis and Rheumatism: Official Journal of American College of Rheumatology. 1999 Jul; 42(7):1322-8

29. Gerards AH, Landewe RB, Prins AP, Bruijn GA, Laan RF, Dijkmans BA. Cyclosporin A monotherapy versus cyclosporin A and methotrexate combination therapy in patients with early rheumatoid arthritis: a double blind randomisedplacebo controlled trial. Annals of the rheumatic diseases. 2003 Apr 1; 62(4):291-6

30. Capell, H.A., Madhok, R., Porter, D.R., Munro, R.A., McInnes, I.B., Hunter, J.A., Steven, M., Zoma, A., Morrison, E., Sambrook, M. and Poon, F.W., Combination therapy with sulfasalazine and methotrexate is more effective than either drug alone in patients with rheumatoid arthritis with a suboptimal response to sulfasalazine: results from the double-blind placebocontrolled MASCOT study. Annals of the rheumatic diseases, 2007; 66(2):235-241.

31. Rau R, Schleusser B, Herborn G, Karger T. Longterm combination therapy of refractory and destructive rheumatoid arthritis with methotrexate (MTX) and intramuscular gold or other disease modifying antirheumatic drugs compared to MTX monotherapy. The Journal of rheumatology. 1998 Aug. 25(8):1485-92.

32. Calgüneri M, Pay S, Caliskaner Z, Apras S, Kiraz S, Ertenli I, Cobankara V. Combination therapy versus monotherapy for the treatment of patients with rheumatoid arthritis. Clin Exp Rheumatol. 1999; 17(6):699-704.

33. Klareskog L, van der Heijde D, de Jager JP, Shoor S. Etanercept plus methotrexate reduced symptoms and disease activity in adult-onset rheumatoid arthritis/COMMENTARY. ACP Journal Club. 2004 Sep 1; 141(2):42.

34. Weinblatt ME, Kremer JM, Bankhurst AD, Bulpitt KJ Fleischmann RM, Fox RI, Jackson CG, Lange M, Burge DJ. A trial of etanercept, a recombinant tumor necrosis factor receptor: Fc fusion protein, in patients with rheumatoid arthritis receiving methotrexate. New England Journal of Medicine. 1999 Jan 28; 340(4):253-9.

35. Burmester GR, Mariette X, Montecucco C, Monteagudo-Sáez I, Malaise M, Tzioufas AG, Bijlsma JW, Unnebrink K, Kary S, Kupper H. Adalimumab alone and in combination with disease-modifying antirheumatic drugs for the treatment of rheumatoid arthritis in clinical practice: the Research in Active Rheumatoid Arthritis (ReAct) trial. Annals of the rheumatic diseases. 2007 Jun 1; 66(6):732-9. 
36. Lipsky PE, van der Heijde DM, St. Clair EW, Furst DE, Breedveld FC, Kalden JR, Smolen JS, Weisman M, Emery P, Feldmann M, Harriman GR. Infliximab and methotrexate in the treatment of rheumatoid arthritis. New England Journal of Medicine. 2000 Nov 30; 343(22):1594-602.

37. Cohen S, Hurd E, Cush J, Schiff M, Weinblatt ME, Moreland LW, Kremer J, Bear MB, Rich WJ, McCabe D. Treatment of rheumatoid arthritis with anakinra, a recombinant human interleukin-1 receptor antagonist, in combination with methotrexate: results of a twenty-four-week, multicenter, randomized, double-blind, placebo-controlled trial. Arthritis \& Rheumatism. 2002 Mar; 46(3):614-24.

38. Genovese MC, Cohen S, Moreland L, Lium D, Robbins S, Newmark R, Bekker P, 20000223 Study Group. Combination therapy with etanercept and anakinra in the treatment of patients with rheumatoid arthritis who have been treated unsuccessfully with methotrexate. Arthritis \& Rheumatism. 2004 May; 50(5):1412-9.

39. Klareskog L, van der Heijde D, de Jager JP, Shoor S. Etanercept plus methotrexate reduced symptoms and disease activity in adult-onset rheumatoid arthritis/COMMENTARY. ACP Journal Club. 2004 Sep 1; 141(2):42.

40. Horneff G, De Bock F, Foeldvari I, Girschick HJ, Michels H, Moebius D, Schmeling H, German and Austrian Paediatric Rheumatology Collaborative Study Group. Safety and efficacy of combination of etanercept and methotrexate compared to treatment with etanercept only in patients with juvenile idiopathic arthritis (JIA): preliminary data from the German JIA Registry. Annals of the rheumatic diseases. 2009 Apr 1; 68(4):519-25.
41. Breedveld FC, Weisman MH, Kavanaugh AF, Cohen SB, Pavelka K, Vollenhoven RV, Sharp J, Perez JL, Spencer-Green GT. The PREMIER study: a multicenter, randomized, double-blind clinical trial of combination therapy with adalimumab plus methotrexate versus methotrexate alone or adalimumab alone in patients with early, aggressive rheumatoid arthritis who had not had previous methotrexate treatment. Arthritis \& Rheumatism: Official Journal of the American College of Rheumatology. 2006 Jan; 54(1):26-37

42. Combe B, Codreanu C, Fiocco U, Geusens PP, Kvien TK, Pavelka K, Sambrook PN, Smolen JS, Wajdula J, Fatenejad S. Etanercept and sulfasalazine, alone and combined in patients with active rheumatoid arthritis despite receiving sulfasalazine: a double blind comparison. Annals of rheumatic diseases. 2006 Oct 1; 65(10):1357-62.

43. O'Dell JR, Haire CE, Erikson N, Drymalski W, Palmer W, Eckhoff PJ, Garwood V, Maloley P, Klassen LW, Wees S, Klein H. Treatment of rheumatoid arthritis with methotrexate alone, sulfasalazine and hydroxychloroquine, or a combination of all three medications. New England Journal of Medicine. 1996 May 16; 334(20):1287-91.

44. O'Dell JR, Leff R, Paulsen G, Haire C, Mallek J, Eckhoff PJ, Fernandez A, Blakely K, Wees S, Stoner J, Hadley S. Treatment of rheumatoid arthritis with methotrexate and hydroxychloroquine, methotrexate and sulfasalazine, or a combination of the three medications: results of a two-year, randomized, double-blind, placebo-controlled trial. Arthritis \& Rheumatism. 2002 May; 46(5):1164-70. 